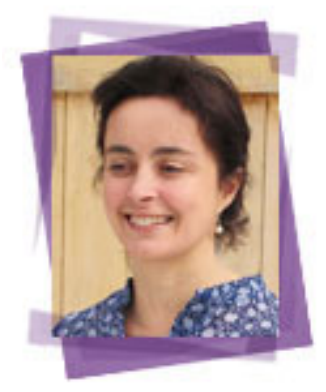

\title{
Translating web multimodalities: Towards inclusive web localization
}

\author{
Maribel Tercedor Sánchez
}

Universidad de Granada

\begin{abstract}
This paper addresses the role of the translator in web localization within the e-inclusion paradigm. We argue that multimodality and forms of accessibility should be offered in an integrated way. Additionally, the aspects that shape the concept of e-inclusion need to be researched from a cognitive and linguistic perspective in the web localization scenarios.
\end{abstract}

\section{Keywords}

web localizacion, translation, accessibity, e-inclusion, multimodality.

\section{Introduction}

Designing with internationalization in mind is a challenge that has been addressed by many actors in the web development fields. However, the emphasis is usually placed on technical aspects, internationalization being most widely understood as "the design and development of a product, application or document content that enables easy localization for target audiences that vary in culture, region, or language" (World Wide Web Consortium 2005). Since a web is potentially accessed by anyone, from any place, designing a web with a global audience in mind is a good practice, regardless of the web being developed to be localized or not. The World Wide Web Consortium (ibid) points that "retrofitting a linguistically- and culturally-centered deliverable for a global market is obviously much more difficult and time-consuming than designing a deliverable with the intent of presenting it globally".

But what is a global market? What is the role of the translator in making a web available and accessible to the "global market"? The web localization and internationalization industry has focussed on the economic advantages of addressing global audiences, hence the term "global market". But more importantly, the web is accessed by people, individuals that are key actors in the present and future of the Internet. Today, user-generated content makes up for $70 \%$ of web content (Manovich 2010), with numbers potentially increasing as new devices make it easier for the user to interact with the web. The move away from the hierarchical structure of the Web 1.0 has resulted in greater interaction, and user-generated content is now present in all fields of knowledge. As an example, in medicine:

The use of Web 2.0 technology to manage health information has given rise to the term "Medicine 2.0" (or Health 2.0), which reflects the use of a specific set of web tools (blogs, Podcasts, tagging, search,Wikis, etc.) by health professionals, researchers, and the public, to generate content, to personalize health services, to collaborate, and to promote multidirectional, interactive health educational experiences (Hughes et al: 2008).

Thus, if we consider the web as today's social medium par excellence, the challenge that we face is that of providing access to those that do not currently have it. This endeavour has been taken aboard by translation NGOs such as the Rosseta Foundation (http://www.therosettafoundation.org), acknowledging the social dimension of the Internet. We argue here that in order to provide access to all, web design, web internationalization and web localization should be considered in the light of e-inclusion. E-inclusion aims to promote literacy and cultural diversity through the use of ICT and hence, the move towards 
internationalization should become a move towards inclusion, in which accessibility and design best practices are taken into account beyond the surface level. The web can be now more global than ever if we follow practices that make of the web an accessible and inclusive medium. In translation, the move towards accessible translation implies, inter alia, providing non-visual equivalents for visual content, non audio equivalents for audio content, but also ensuring that people with different levels of expertise can access information and interact with the web.

Accessibility is closely related to usability and concerns tools, content and format. Tools and format have received a great deal of attention, especially in the web developing industry. However, content issues have not yet been addressed in depth, which is not surprising since in current practices of usability and web design the focus is clearly on layout and technical aspects. In this article the focus will be on content, and we will in turn consider some aspects that shape the role of the translator in contributing to an inclusive web.

\section{Web texts, e-inclusion and the translator's tasks}

Web texts challenge traditional text typologies. The web is characterized by a hybridization of text types and genres. Furthermore, traditional taxonomies of text types are inadequate because they do not take into account multimodality and interactivity. Aspects such as the life span of a text are playing a defining role in new typologies, rising new questions for translation research such as: Should the translator's position towards treating neology or avoiding interference differ depending on the "durability" of a text? Should translation quality assessment take this factor into account? E-texts such as pdf documents resemble other traditional text types and have indeed a longer life cycle than other texts which are not designed to be printed or to last. In contrast, texts produced spontaneously as a comment for a blog are published unrevised and probably have a shorter life cycle, though their communicative function might be important, as is indeed their relevance in web-as-corpus research, since they provide textual features that resemble oral communication.

New superstructures appear everyday, and the growing evidence of research on gaze plots obtained through eye-tracking techniques (e.g. Nielsen 2010) challenge the F-Pattern of screen reading and show variation depending on aspects such as text structure, interface, advertisement positioning, color, presence of images or length. However, to our knowledge there is still little data looking into fine-grained linguistic, cultural and cognitive aspects of attention and comprehension during the use of translated webs. This type of research will doubtlessly offer useful insights into the design and localization issues of new text types and genres.

The new text formats, genres and types have contributed to the diversification of tasks carried out by the translator, who now works with a greater demand of skills and management of tools. Tasks that entail assessment of different criteria of cultural, cognitive and linguistic adequacy of a product for a target audience are commonplace in the web translation scenarios. It is a usual practice to work as language consultants and carry out tasks of cultural assessment of products prior to the localization process. Aiming at individuals, websites need to tackle terminological expectations, appropriate metaphors, colors, perceptions. To look into these issues, we have adapted an industry form to reflect on issues of cultural and linguistic appropriateness within localization courses. 


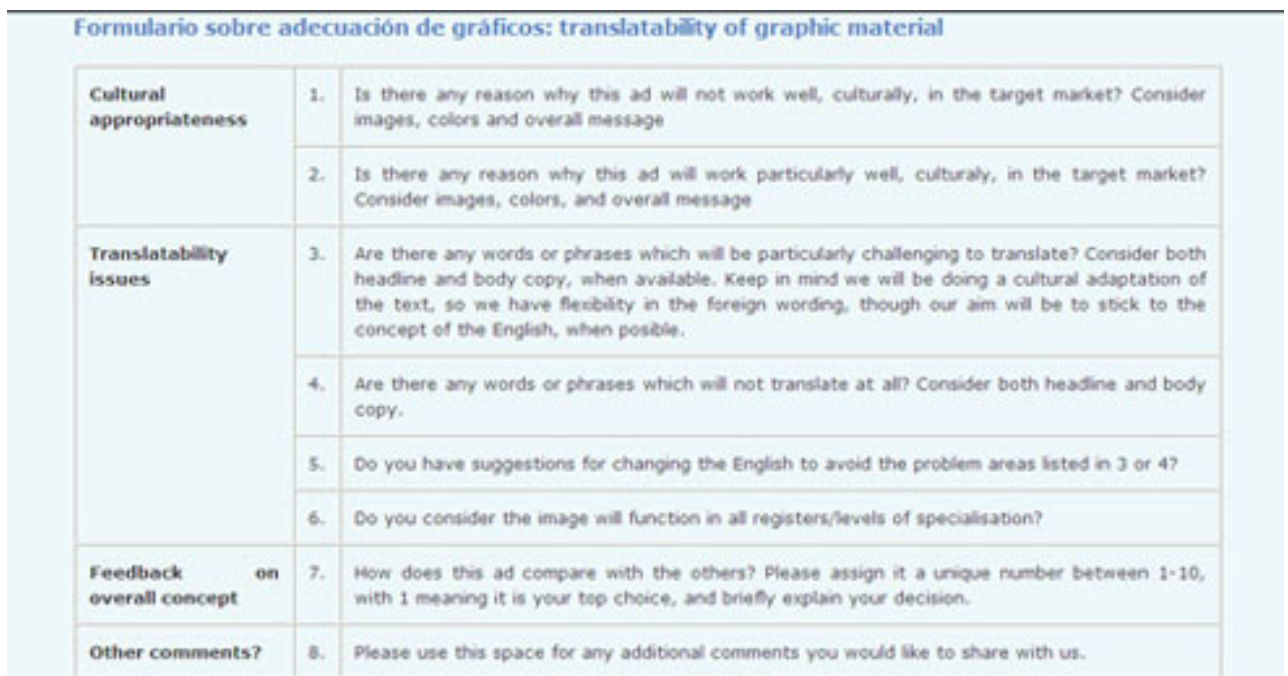

Figure 1. Example of linguistic and cultural form. Source: http://www.ugr.es/local/imagenytexto.

As part of the cultural and linguistic issues, and considering the assumption that we translate for as wide an audience as possible within the targeted group, the translator should be able to tackle the issues that make it difficult for a person to understand and interact with the web. According to a recent workshop on einclusion at the European Commission, one out of every three persons in the EU is not benefiting from ICT due to problems of disabilities, age, education, unemployment or geographical issues (González Sancho 2009). In this regard, the considerations for a web for all entail following accessibility criteria in translation practices. Within these, the translator can be a key actor if we lead training efforts to developing methodologies to provide alternative formats and address the different information needs with regard to level of literacy and specialization. Furthermore, the translator can carry out assessment and editing work to ensure the most appropriate use of terminology, typographical conventions, style, following accessibility criteria as part of internal quality assurance testing of a web site (López et al 2009).

\section{Multimodal texts in the web: Cognitive benefits of providing accessible and integrated materials}

Multimodality in the web -information presented through different channels and signs- has provided a landscape of new ways of working and new tasks. In Translation Studies, the concept of accessibility within these scenarios has now been extensively addressed by researchers and professionals alike. The focus has been on developing technical and linguistic guidelines towards providing alternative formats for people with disabilities, and the fact that accessibility benefits all has been addressed. Since working from the concept of accessibility benefits not only people with disabilities but everyone, new venues of research include tackling precisely how we as translators can contribute to improving the textual, cognitive and cultural quality of accessible formats when faced with both interlinguistic translation and intralinguistic tasks.

Research in the cognitive sciences and psychology points to the relevance of cognition and perception in all levels of web use, the information search process being cognitive in nature and the interaction with computing devices and the expectations on information retrieval relying both on cognition and perception. Studies point to importance of providing integrated materials, i.e. materials that are interconnected in order for an information structure not to impose an excessive cognitive load on the user (for a review of approaches to measuring cognitive load in web use see Gwizdka, forthcoming). It is often hypothesized that if multimodal texts bear no relation or are superfluous to the main theme of the medium, the efforts may be cognitively demanding and attention may be directed away from the main topic. Integrating 
information provided in different formats is not new or exclusive of the web, and its benefits for learning, as well as the unnecessary cognitive load posed by redundant materials, have been extensively studied in cognition (e.g. Chandler and Sweller 1991; Ward and Sweller 1990).

Additionally, considering that one of the main functions of the web is to provide the user with new information, aspects such as world knowledge and previous knowledge should play a role in the web development and localization processes, and they have been identified as key factors in determining the cognitive load posed by new information (Moreno 2006).

Multimodality has important benefits for learning, since the capacity of our working memory can be increased by connecting different sources of information, such as those provided by multimodal formats. From an educational perspective, «the instructional designer effectively reduces extraneous cognitive load by helping the student "off-load" some essential processing from the visual channel to the auditory channel» (Smith and Ragan, 2005). Hypermedia has also been underlined as a medium that mimics the process of human learning through the connection of nodes of information by links. Most importantly, the recent findings within the cognitive sciences pointing to areas of common representation of gestures, facial and bodily expressions, materials, objects and verbal language in the brain challenge the traditional specialization of language areas in the brain and bring about new venues of research that connect modalities in relation to communication (e.g. Lotze et al 2006; Lawrence et al 2006; Clark 2005; Tylén et al 2009).

Considering these premises, the translator doing accessible translations can work in the integration of channels of information and content that is coherent with the user's previous knowledge and level of expertise, avoiding information that is superfluous. Integrating channels is carried out providing alternative formats, and this means doing intersemiotic translation that entails for example translating the visual into language, be it for audiodescription, subtitling, or plain text for the web in the form of descriptions. For example, Tercedor and Prieto propose in the following illustration how integrating an explanation of a graph is a form of interlinguistic and intersemiotic translation that entails translating and converting visuals into language following accessibility criteria.

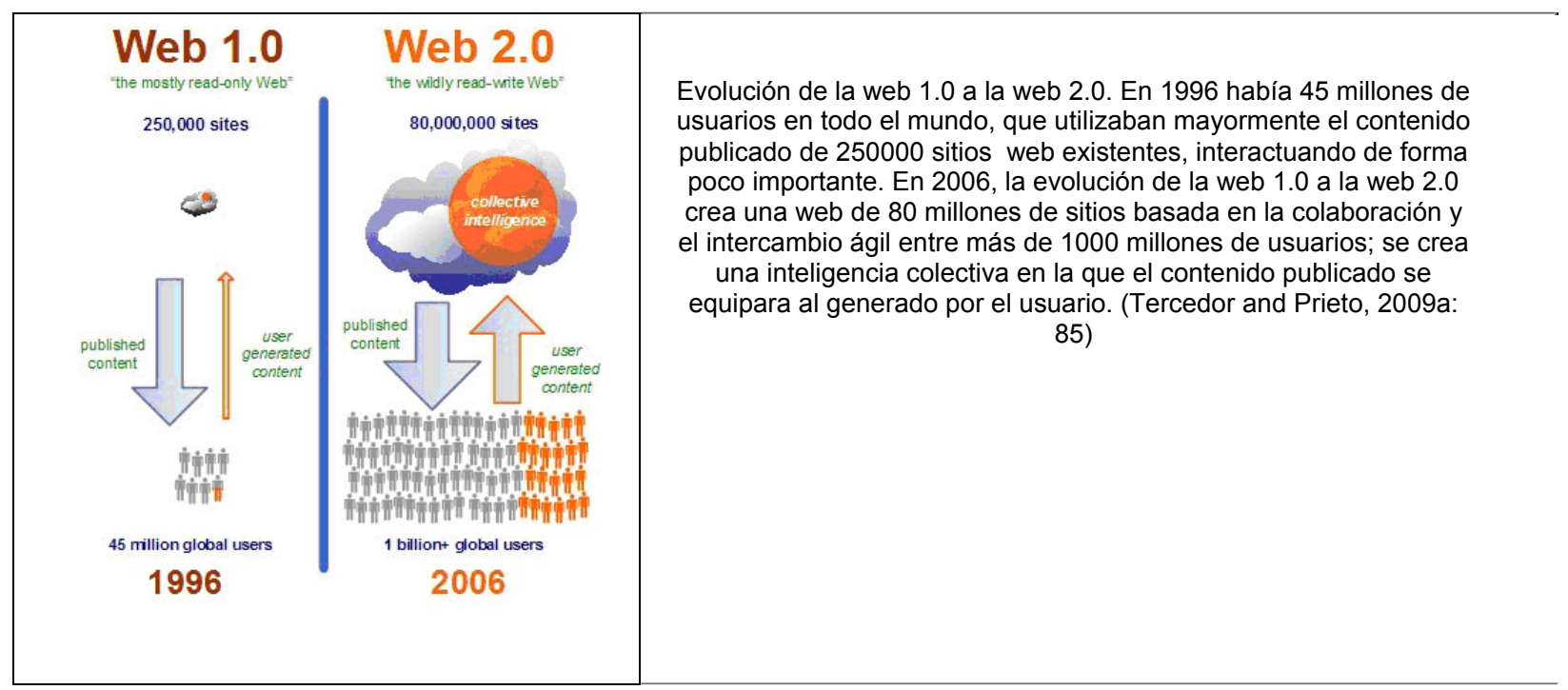

Figure 2. Example of accessible image description.

The understanding of the graph above becomes facilitated to all users through the textual description of it. Many web authoring tools of general use, such as Adobe Dreamweaver, have actually incorporated a 
prompt to ask designers -and translators- to provide a text equivalent for an image. This task interconnects interlinguistic and intersemiotic translation with technical writing, providing an essential skill in web environments. Additionally, this type of practice can be a good technique when budget limits hinder the total localization of an image, especially when the embedded text has not been provided layered. This sort of task helps develop introductory techniques for audiodescription. The different parameters connecting image description and audiodescription are analyzed in Jiménez et al (2009: 109).

Integrated channels of information should ideally be tailored to different user-types, i.e. they should be provided in such a way that they can be activated according to particular needs. Since the web is used differently by different individuals, formats should be considered to suit different user types. Such is the case of the following example of an educational video in which captions and audiodescription are available optionally.

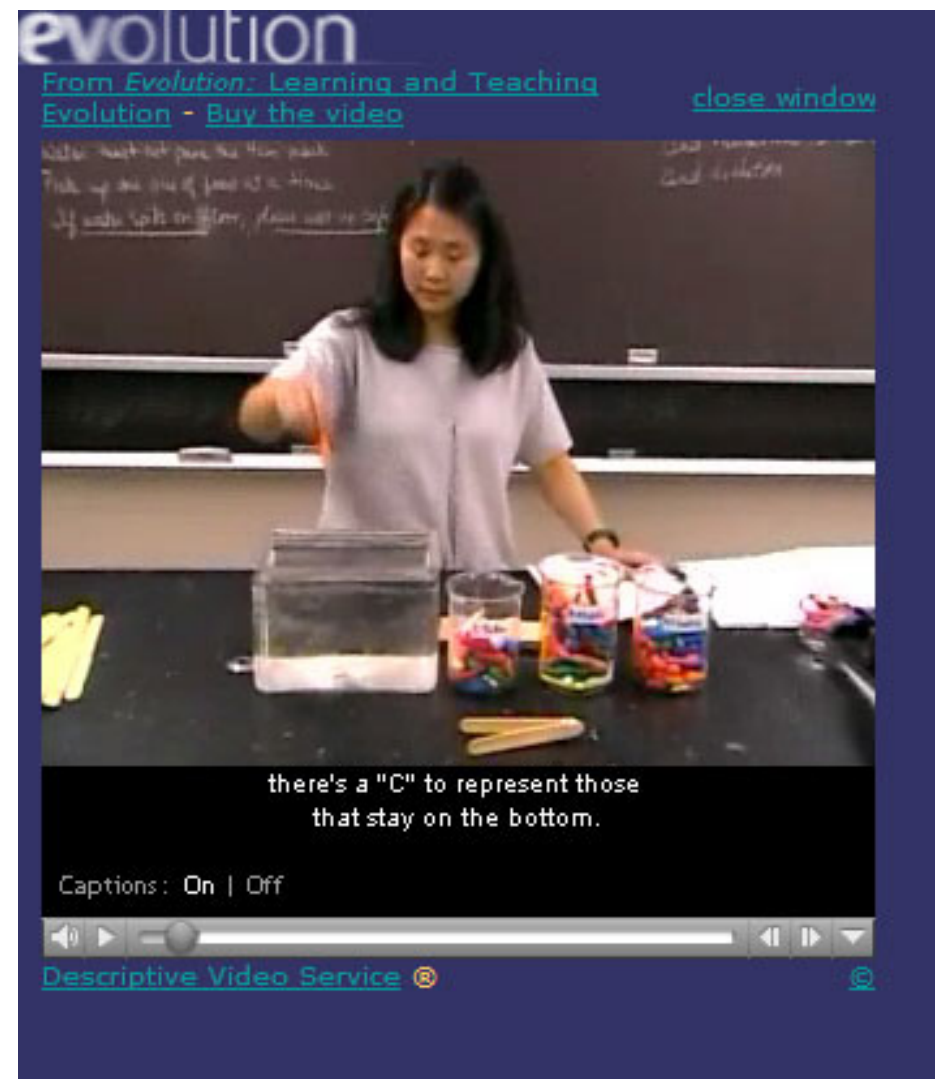

Figure 3. Integrated accessible formats optionally activated. Source: http://www.pbs.org/wgbh/evolution/library/11/1/quicktime/e m 3 dvs.html

Another task that connects translation and technical writing with accessibility issues is providing terminology in different levels. For example, providing definitions for concepts that are specialized constitutes an essential step in an accessible translation of a web that is aimed at the general public. The notion of level of expertise is part of the concept of accessibility: «new multimedia formats allow for information to be accessible not only to people with disabilities but also to people having different levels of knowledge» (Tercedor et al 2009b: 155).

The following encyclopaedic article provides the user with three different types of definitions, as marked in the black boxes. 

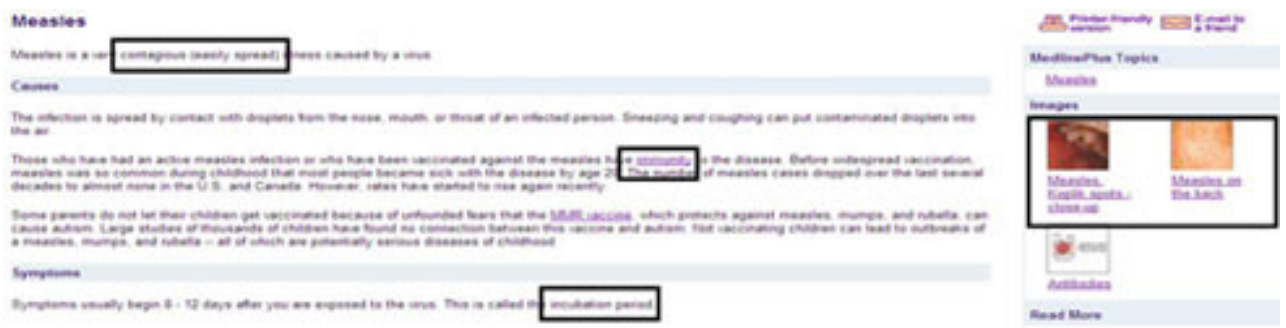

Figure 4. Definitions provided to address the lay audience in Medline encyclopaedia. Source: http://www.nlm.nih.gov/medlineplus/ency/article/001569.htm

In the first case, the use of parenthesis (“...contagious (easily spread)...") leads the user to skim through the information, unless there is a need to pay attention to the definition. In the second case, a hyperlink provides a new entry in the encyclopaedia ("immunity"), through a hyperlink that constitutes a traditional user-activated format in the web. In the third case, the definition is provided before the actual term, "incubation period", and connected with it cohesively. All three forms of definitions provide information to the lay audience that typically uses this web. From an interlinguistic perspective, the previous knowledge of the target audience may be different to that assumed for the audience of the source text, thus demanding a change in the level of expertise determined in the definitions. This is particularly common in the translation of Greek or Latin root terms and definitions in the EN-ES language combination, where there is often common world knowledge of Greek or Latin root terms in Spanish lay audiences (eg. amigdalitis, cefalea, etc).

It is interesting to note the importance of providing visual sources of information, such as in the article above. In fact, visual aspects of certain types of concepts, such as in the case of maps, illnesses, species of plants or animals, are essential since there are concepts that our mind typically represents visually through perceptual features of color, texture, material, perspective. The integrated information provided should thus include these features and provide with alternative formats to describe them. In this regard, studying lexical aspects used for perceptual information can be crucial in determining the lexical items that best suit a particular description of sounds, textures, perspectives, etc. Special corpora (e.g. of subtitles, audiodescriptions, literary genres) can offer important information on the lexicalizations of different perceptual concepts that can be classified according to semantic domains. As an example, the following concordances of the lemma "texture" in the Corpus of Contemporary American English can help the translator to choose relevant adjectives to describe images.

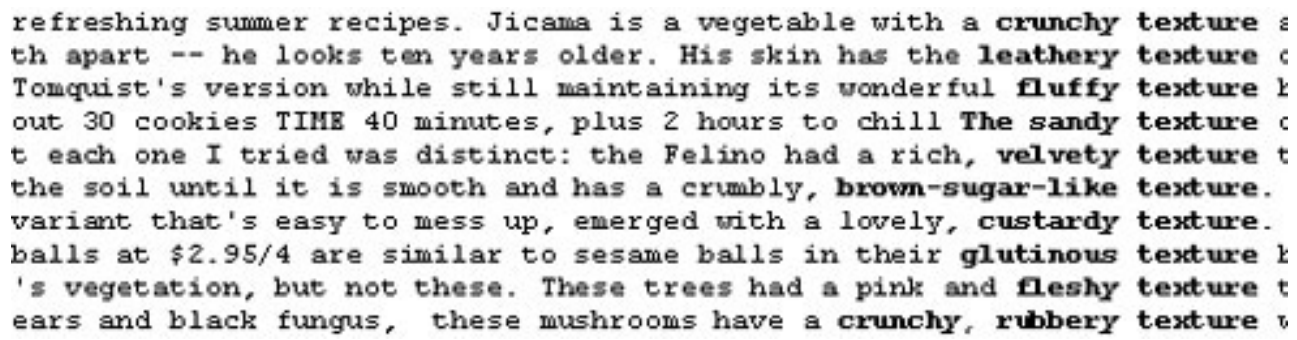

Figure 5. Left sorted random concordances of the lemma 'texture' in the oral section of the Corpus of Contemporary American English: http://www.americancorpus.org/

Finally, reflecting on standards of textuality (Beaugrande and Dressler 1981: 3) in the light of e-inclusion might be a good start in considering localization as a key activity to provide the web with basic features towards granting access for all. In this respect, situationality can be redefined here as the new communicative situation that the translator has to address following intentionality of the sender and in order to provide a web for all. A simple consideration about whether we are incorrectly assuming that other people see their world and do things in the same way as we do might suffice. 
If we focus on acceptability and informativity, well-developed alternative formats will ensure that the web provides users with information that is relevant and can be accessed by all, contributing to meet user's expectations of usability. Intertextuality in this case is materialized through the connection between the information assumed in the user and that provided in all integrated formats, which should be coherent and cohesive, i.e. well interconnected in the macrostructural and microstructural level and relevant. For example, the translator must assess if the presence of a particular style in a web has a decorative function, and thus little impact on accessibility, or if it has been placed there with an intention, and thus, it needs to be transferred to different formats. This can be the case with a particular font type, layout or color. Color in fact might be superfluous in informative load or carry important connotative meanings.

\section{Conclusions}

In this article we have analyzed some issues of accessibility and e-inclusion that concern the work of the translator in multimodal web contexts. Research venues have been explored through some examples of accessible translation tasks, and the cognitive benefits of integrating formats of information have been pinpointed.

\section{References}

Beaugrande, de R. and Dressler, W. (1981). An introduction to text linguistics. London: Longman.

Chandler and Sweller, J. (1991). "Cognitive Load Theory and the format of instruction". Cognition and instruction 8-4, 293-332.

Clark, H. (2005). "Coordinating with each other in a material world". Discourse studies 7, 507-525.

González-Sancho M. (2009). "ICT for health, aging, and inclusion". Workshop on European activities on e-Inclusion, January 27 th 2009 , Brussels.

http://ec.europa.eu/information society/activities/einclusion/docs/workshop $0109 /$ report.pdf Last updated: 27-1-09. Last accessed: 29.6.10

Gwizdka, Jacek. Forthcoming. "Distribution of cognitive load in web search". Journal of the American Society of Information Science and Technology.

Hughes B, Joshi I, Wareham J. (2008). "Health 2.0 and medicine 2.0: tensions and controversies in the field". J Med Internet Res 2008;10:e23.

Jiménez C., Seibel C. and Chica A. (2009). "Accesibilidad e inclusión en los textos multimodales: la audiodescripción de la imagen dinámica". Tercedor M. (ed.) Materiales multimedia para todos: inclusión y accesibilidad en educación. Granada: Tragacanto. 89-111.

Lawrence, E.J., Shaw, P., Giampietro, V.P., Surguladze S., Brammer M.J and Davis A.S. (2006). "The role of "shared representations" in social perception and empathy: an fMRI study". Neuroimage 29(4), 11731184.

López Rodríguez C.I., Prieto Velasco J.A. and Tercedor Sánchez M. (2009). "Sharing environmental information through multilingual terminological and multimedia resources: the role of accessibility in increasing public awareness towards sustainable growth". En J. Hřebíček et al. (eds.), Towards eEnvironment. Opportunities of SEIS and SISE: Integrating Environmental Knowledge in Europe. 598-605. Prague: Masaryk University. 


\section{$\gg>$ revista tradumàtica}

Traducció i Tecnologies de la Informació i la Comunicació

Número 08: Localització i web : desembre 2010 :

http://www.fti.uab.cat/tradumatica/revista : ISSN: 1578-7559

Lotze, M., Heymans, U., Birbaumer, N., Veit, R., Erb, M., Flor, H. (2006). "Differential cerebral activation during observation of expressive gestures and motor acts". Neurophsychologia, 44, 1787-1795.

Manovich, L. (2010). “La era de los 'more media”. El país 1/5/2010.

http://www.elpais.com/articulo/portada/era/more/media/elpepuculbab/20100501elpbabpor 1/Tes

Moreno, R. (2006). "When worked examples don't work: Is cognitive load theory at an impasse?" Learning and Instruction, 16, 170-181.

Nielsen, J. (2010). "Scrolling and attention". http://useit.com/alertbox Last updated: 22.3.10

Smith, P. L., \& Ragan, T. J. (2005). Instructional design (3rd ed.). Indianapolis, IN: Wiley.

Tercedor M. and Prieto Velasco J.A. (2009a). "Aprender con imágenes". Tercedor M. (ed.) Materiales multimedia para todos: inclusión y accesibilidad en educación. Granada: Tragacanto.

Tercedor M., Alarcón E., Prieto J.A., López C.I. (2009b). "Images as part of technical translation courses: implications and applications". Jostrans: The Journal of Specialised Translation 11, 143-168.

Tylén K., Wallentin M., Roepstorff A. (2009). "Say it with flowers! An fMRI study of object mediated communication”. Brain and Language 108 (2009), 159-166.

Ward, M. and Sweller, J. (1990). "Structuring effective worked examples". Cognition and Instruction, 7, 139.

World Wide Web Consortium. (2005). "Localization vs internationalization". Available at: http://www.w3.org//nternational/questions/qa-i18n.en.php Last updated: 5.12.05. Access date: 5.7.10 